\title{
Zika Vírus e o Futuro da Odontologia no Atendimento a Pacientes com Microcefalia
}

\author{
Zika Virus and the Future of Dentistry in Patient Carewith Microcephaly
}

Sângela Maria da Silva Pereira ${ }^{1}$, Alberto Sabin Moura Borba ${ }^{1}$, Jaqueline de Fátima Lopes Rosa ${ }^{1}$, Ceci Nunes Carvalho ${ }^{2}$, Etevaldo Matos Maia Filho ${ }^{2}$, Meire Coelho Ferreira ${ }^{2}$, Cristina de Andrade Monteiro ${ }^{3}$, Eduardo Buozi Moffa ${ }^{2,3}$

\begin{abstract}
Resumo: O Zika Vírus (ZIKV) é um arbovírus, que tem o ácido ribonucleico como seu material genético, pertence a família Flaviviridae e é transmitido principalmente pelos mosquitos Aedes aegypti e Aedes albopictus, tendo-se registros também da sua transmissão por fluídos corporais. Desde Maio de 2015 o Brasil enfrenta um surto do vírus, que se espalhou rapidamente pelas Américas causando preocupação devido a possível relação do vírus com a microcefalia, que foi detectada no líquido amniótico e placenta de mulheres com fetos microcéfalos. Os pacientes acometidos com microcefalia possuem um perímetro cefálico inferior à média para o sexo e idade, e na maioria dos casos está associado à estrutura cerebral alterada, problemas de desenvolvimento e características faciais dismórficas. Estas características afetam não apenas o estado de saúde geral do paciente, mais também o atendimento odontológico, que se torna dificultado devido ao pequeno número de profissionais habilitados para 0 atendimento a pacientes especiais e ao pouco conhecimento das características craniofaciais e dentárias destes indivíduos. O presente artigo tem como objetivo apresentar as características craniofaciais que influenciam no atendimento odontológico e uma perspectiva sobre o futuro da odontologia no atendimento dos pacientes acometidos com microcefalia.
\end{abstract}

Palavras-chave: Microcefalia, manifestações orais, Vírus Zika

\begin{abstract}
The Zika virus (ZIKV) is an arbovirus of the Flaviviridae family transmitted through the bite of the Aedes aegypti and Aedes albopictus mosquitos. Additionally, there are reports of its transmission by body fluids. Since May 2015, Brazil is facing an outbreak of the virus, which had quickly spread across the Americas leading to several concerns. The possible relationship of the Zika virus with the microcephaly is documented, given its detection in amniotic fluids and placenta of women with microcephalic fetuses. Patients with microcephaly presents lower head circumference compared with the average for the same sex and age, which is generally, associated with disturbed brain structure, development problems and dimorphism in facial structures. These features affect not only the general health of the patient, having also relevant impacts on the dental care, in which the major difficulties are related to the lack of knowledge on craniofacial and dental structures of these individuals as well as the scarcity of qualified professionals for the dental treatment of special patients. This article aims to present the craniofacial features that influence the dental care and a perspective on the future of dentistry in attending affected patients with microcephaly.
\end{abstract}

Keywords: Microcephaly, oral manifestations, Zika virus

1 - Discente do Programa de Pós-Graduação em Odontologia Integrada - Universidade CEUMA

2 - Docente Assistente Doutor do Programa de Pós-Graduação em Odontologia Integrada, Universidade CEUMA, São Luís - Maranhão, Brazil;

3 - Docente Assistente Doutor do Programa de Pós-Graduação em Biologia Parasitária, Universidade CEUMA, São Luís - Maranhão, Brazil 


\section{Introdução}

O Zika Vírus (ZIKV) é um arbovírus, que tem $\mathrm{o}$ ácido ribonucleico como seu material genético. Ele pertence ao gênero do Flavivírus, família Flaviviridae. Alguns estudos relatam três linhagens principais de ZIKV, uma original da Ásia e duas da África, que até o século XX não causaram infecções significativas aos seres humanos ${ }^{1}$. É transmitido principalmente pelos mosquitos Aedes aegypti e Aedes albopictus $^{2}$, mas se têm registros da transmissão por fluídos corporais como sangue ${ }^{3}$, sêmen ${ }^{4}$, urina ${ }^{5}$ e saliva ${ }^{6}$.

$\mathrm{O} Z \mathrm{ZIKV}$ foi isolado pela primeira vez em 1947, em macacos Rhesus na floresta Zika da República do Uganda, África ${ }^{7}$, e relatado em humanos pela primeira vez em 1954 na África Ocidental $^{8}$. Em seguida, o vírus se espalhou para a Indonésia, Micronésia, Tailândia, Filipinas, Polinésia Francesa, Ilha da Pascoa (Chile) e llhas do Pacífico em 2014,911. Na América do Sul o vírus não havia sido documentado até o primeiro relatório da transmissão autóctone no Brasil em maio de $2015^{12}$. Naquela época foi concluído que o ZIKV foi introduzido no Brasil na copa do mundo de futebol em 2014, através de viajantes do Chile, no entanto Peterson et al. $^{2}$ concluem que essa ideia não é fundamentada, pois países do pacífico, região acometida com surtos de ZIKV, não competiram na copa do mundo de 2014. Entretanto, os países do pacífico haviam participado em agosto de 2014 do campeonato mundial de Va'a no Rio de Janeiro, sugerindo que a introdução do ZIKV pode ter ocorrido em seguida ${ }^{2}$.

\section{Zika vírus e microcefalia}

Desde sua introdução no Brasil, em maio de 2015, o ZIKV brasileiro (ZIKVBR) se espalhou rapidamente por todo o país e nas Américas. Associado ao surto do ZIKV ocorre o recente aumento dos casos de microcefalia no Brasil. Em novembro de 2015, o Ministério da Saúde divulgou 0 primeiro boletim epidemiológico sobre microcefalia relatando um grande aumento no número de casos na região Nordeste, onde foram notificados 399 casos, sendo 268 no estado do Pernambuco. O Ministério da Saúde ainda sugeriu uma possível associação dos casos de microcefalia com a infecção pelo Zika Vírus (ZIKV), a partir de uma investigação do Laboratório de Flavivírus do Instituto Oswaldo Cruz, onde constataram a presença do genoma do ZIKV em amostras de líquido amniótico de duas gestantes da Paraíba com fetos microcéfalos confirmados através de exames de ultrassonografia ${ }^{13}$.

A detecção do ZIKVBR no liquido amniótico, na placenta de mulheres com fetos microcéfalos e no sangue de recém-nascidos, sugere que o vírus pode ultrapassar a membrana placentária $^{13,14}$. O vírus também foi identificado no cérebro de fetos microcéfalos ${ }^{13}$, no entanto, ainda estão sendo realizadas pesquisas para comprovação da associação do ZIKVBR com malformações cerebrais.

Um estudo recente, realizado por Cugola et al. ${ }^{1}$, mostra que o ZIKVBR causa defeitos permanentes em modelos experimentais. Após a infecção de camundongos com 0 ZIKVBR observou-se que este causa restrição do crescimento intra-uterino, com sinais de microcefalia. Além disso, 0 vírus infecta células progenitoras corticais, levando a um 
aumento da morte celular. Estes resultados indicam que ZIKVBR atravessa a placenta e provoca microcefalia, infectando as células progenitoras corticais, induzindo a morte celular por apoptose e autofagia e prejudicando assim 0 desenvolvimento neurológico.

Segundo a Organização Mundial da Saúde $(\mathrm{OMS})^{15}$, a microcefalia é uma desordem onde a circunferência da cabeça é dois (-2) desvios padrão ou menor do que a média para o sexo e idade, podendo estar associada, em alguns casos, com estrutura cerebral alterada e problemas de desenvolvimento neurológico. As microcefalias têm etiologia complexa e multifatorial, envolvendo fatores genéticos e seu diagnóstico se dá principalmente pela medição do perímetro cefálico (PC), procedimento comum no acompanhamento clínico do recém-nascido visando à identificação de doenças neurológicas.

0 estudo de Cugola et al. ${ }^{1}$ evidencia a relação entre o ZIKVBR e a microcefalia, sendo esta malformação também uma das principais características da síndrome de Angelman ${ }^{16}$, síndrome Velo-cardiofacial $^{17}$, síndrome de Langer-Giedion ${ }^{18}$ e síndrome de Miller-Dieker ${ }^{19}$.

Em geral, recém-nascidos com microcefalia apresentam alterações no desenvolvimento neuropsicomotor ${ }^{20}$. A microcefalia pode ser acompanhada de epilepsia, paralisia cerebral, retardo no desenvolvimento cognitivo, motor e fala, além de problemas de visão e audição ${ }^{21}$.

\section{Características craniofaciais de pacientes com microcefalia}

Características clínicas de pacientes microcéfalos oriundos de diferentes causas têm sido relatadas em diversos estudos. Estas características são importantes, pois com o crescimento do número destes pacientes é necessário um investimento em uma equipe multidisciplinar capaz de responder a todas as necessidades destes indivíduos e suas famílias.

Um estudo realizado por Nimmakayaly et al. $^{22}$ descreveu um paciente com microcefalia congênita grave, sendo sua causa avaliada por estudos cromossômicos, teste de rastreamento de $\mathrm{TORCH}$ (Toxoplasmose, Rubéola, Citomegalovírus, Herpes simples e HIV), citomegalovírus urinário e tomografia computadorizada da cabeça. $\mathrm{O}$ paciente apresentou cisto do ducto tireoglosso, perda auditiva neurossensorial, traqueomalácia leve, hipertensão pulmonar, atraso no desenvolvimento, comprometimento da deglutição e hipotonia muscular. $\mathrm{O}$ estudo cromossômico revelou uma associação à microdeleção da região do cromossomo 17q22q23.2. As informações clínicas do paciente descreveram dimorfismos facial e episódios de apnéia, um deles resultando em uma parada cardiovascular. Após exames otorrinolaringológicos foi detectada normalidade na via área superior $e$ laringomalácia leve com colapso das pregas ariepiglóticas na inspiração calma.

Morava et al. ${ }^{23}$ descreveram as características clínicas e bioquímicas de três pacientes diagnosticados com transtorno congênito da glicolisação. Destes, dois apresentaram microcefalia ao nascer e um microcefalia progressiva. Os pacientes apresentaram hipotonia muscular, atraso de crescimento grave, testa estreita e plana, região malar plana, nariz amplo e curto, microstomia, retrognatia e pescoço curto com pele enrugada, sendo que somente um dos pacientes apresentou hipertelorismo. 
Morava et al. ${ }^{24}$ ainda descreveram as características de sete pacientes com síndrome Cutis laxa autossômica recessiva neonatal (ARCL) associada a defeitos congênitos de glicosilação. Todos os pacientes foram submetidos a investigações oftalmológicas, audiológicas, PEATE (Potenciais Evocados Auditivos de Tronco Encefálico), EEG (Eletroencefalo-grama), ressonância magnética do crânio e raio-x do crânio e tórax. Dos sete pacientes, quatro tiveram microcefalia congênita acompanhada de características como braquicefalia, hipoplasia da face média, face plana, hipotonia, lábio fino, palato atrésico, retrognatismo, desenvolvi-mento psicomotor atrasado, palato profundo e dimorfismo facial.

Sete indivíduos com microdeleções no cromossomo 17q23, foram estudados por Ballif et al. ${ }^{25}$ que relataram suas características clínicas e moleculares. Destes, quatro indivíduos apresentaram microcefalia e um, microcefalia relativa. Os autores descreveram as seguintes características faciais dos pacientes microcéfalos: sobrancelhas altas, dobras epicânticas do lado direto, hipertelorismo, ponte nasal e terço médio achatado, plagiocefalia, crânio em forma de caixa, fontanela anterior aberta, testa proeminente, nariz pequeno com ponta nasal bulbosa, microstomia, orelhas pequenas, micrognatia mandibular, orelhas protuberantes e microstomia.

Mickelson et al. ${ }^{16}$ relataram uma menina com fenótipo e perfil de desenvolvimento inicialmente sugestivos de síndrome de Angelman, que subsequentemente mostrou uma deleção de 17q23.1q23.3. A menina apresentou microcefalia, retardo no crescimento, atraso no desenvolvimento e características craniofaciais como: braquicefalia, achatamento occipital, micrognatia suave, rosto redondo, boca voltada para baixo, palato anormal e amplo espaço entre os dentes.

\section{Futuro da odontologia}

As características dos pacientes microcéfalos foram descritas em diversos artigos e os enquadram como pacientes com necessidades especiais, que são indivíduos que apresentam alterações mentais, físicas, orgânicas, sociais e/ou comportamentais e necessitam de atendimento diferenciado ${ }^{27}$. As características de relevância para o atendimento odontológico foram resumidas na tabela 1.

Siqueira et al. $^{27}$ especulam que o número crescente de casos de microcefalia associado ao ZIKV, no futuro próximo, não afetará significativamente apenas o estado geral de saúde de seus pacientes, mais também o custo de atendimento odontológico nos países afetados por essas condições. $\mathrm{Na}$ maioria dos casos, o cirurgião-dentista encontra-se despreparado e inseguro diante destes pacientes, o que é dificultado pelo pouco conhecimento que possuem das suas principais características bucais e craniofaciais. Com isso, o profissional fica impossibilitado para determinar procedimentos clínicos a serem realizados.

Além disso, estima-se que hoje no Brasil o número de profissionais habilitados para o atendimento desses pacientes é reduzido. De acordo com o Conselho Federal de Odontologia são 583 inscritos como especialistas em Pacientes com necessidades especiais (PNE) em todo o território brasileiro até Agosto de 2016, um número baixo levando em consideração que 23,91\% da população brasileira possui algum 
tipo de deficiência de acordo com o censo de 2010 do Instituto Brasileiro de Geografia e Estatística e, 1845 casos de microcefalia e/ou alteração do SNC já foram confirmados até Agosto de 2016 de acordo com 0 informe

Tabela 1. Características dos pacientes com microcefalia

\begin{tabular}{|c|c|c|c|c|c|c|c|c|c|c|c|c|c|c|}
\hline Paciente & $1^{22}$ & $2^{24}$ & $3^{24}$ & $4^{24}$ & $5^{24}$ & $6^{23}$ & $7^{23}$ & $8^{23}$ & $9^{23}$ & $10^{23}$ & $11^{23}$ & $12^{23}$ & $13^{23}$ & $14^{26}$ \\
\hline Idade & 4 anos & $\begin{array}{c}6 \\
\text { mês }\end{array}$ & $\begin{array}{c}1^{\mathrm{a} e} \mathrm{e} \\
10\end{array}$ & $\begin{array}{c}5 \\
\text { mês }\end{array}$ & $\begin{array}{c}4^{a} \mathrm{e} \\
8 \\
\text { mês }\end{array}$ & RN & $\mathrm{RN}$ & $\mathrm{RN}$ & $\begin{array}{c}3 \\
\text { anos }\end{array}$ & $\begin{array}{c}5^{\mathrm{a}} \mathrm{e} \\
1 \\
\text { mês }\end{array}$ & 4 & $\begin{array}{c}4 \\
\text { mês }\end{array}$ & $\begin{array}{c}1^{\mathrm{a}} \mathrm{e} \\
10 \\
\text { mês }\end{array}$ & $\begin{array}{c}4,5 \\
\text { anos }\end{array}$ \\
\hline Sexo & Fem & Fem & Fem & Fem & Mas & Fem & Mas & Fem & Fem & Fem & Mas & Fem & Fem & Fem \\
\hline $\begin{array}{l}\text { Circunferência } \\
\text { do crânio }(\mathrm{cm})\end{array}$ & 30,5 & 30,8 & 30,5 & 31 & 30 & 31,5 & 33,5 & 31,9 & - & - & - & - & - & 47 \\
\hline $\begin{array}{lr}\text { Atraso } & \text { no } \\
\text { desenvolvimento }\end{array}$ & + & + & + & + & + & + & + & + & + & + & + & + & + & + \\
\hline Hipotonia & + & + & + & - & + & + & + & + & - & - & - & + & - & + \\
\hline Microstomia & - & - & - & - & - & + & + & + & - & - & - & + & - & - \\
\hline $\begin{array}{l}\text { Dimorfismo } \\
\text { facial }\end{array}$ & + & + & + & + & + & + & + & + & + & + & + & + & + & + \\
\hline Micrognatia & - & - & - & - & - & + & + & + & - & - & - & - & + & + \\
\hline Retrognatia & - & - & - & + & - & + & + & + & - & - & - & - & - & - \\
\hline Palato anormal & - & - & - & + & + & - & - & - & - & - & - & - & - & + \\
\hline $\begin{array}{l}\text { Amplo espaço } \\
\text { entre os dentes }\end{array}$ & - & - & - & - & - & - & - & - & - & - & - & - & - & + \\
\hline
\end{tabular}

epidemiológico 33/2016 do Ministério da Saúde ${ }^{28}$.

A especialidade Odontologia para Pacientes com necessidades especiais tem como objetivo o diagnóstico, a prevenção, o tratamento e o controle dos problemas de saúde bucal dos pacientes que apresentam uma complexidade no sistema biológico e/ou psicológico e/ou social, bem como a percepção e a atuação dentro de uma estrutura multidisciplinar.

Os pacientes com microcefalia constituem um grupo de alto risco para o desenvolvimento de doenças bucais. O atraso no desenvolvimento devido à hipotonia muscular pode levar a atrasos secundários na aquisição de habilidades motoras. No caso destes pacientes, 0 atraso das habilidades motoras é o principal fator para o atraso no desenvolvimento de suave a moderado ${ }^{22}$, que leva a maioria a não apresentar plena capacidade de realizar seus cuidados bucais, tornando o paciente dependente de um cuidador para realização da higiene oral, que em alguns casos pode ser dificultada pela presença de microstomia.

A cabeça dos pacientes microcéfalos é desproporcionalmente menor que o restante do corpo, sendo relatado a presença de dismorfismo facial por Mickelson et al. ${ }^{16}$, Morava et al. $^{23}$, Morava et al. ${ }^{24}$, Ballif et al. ${ }^{25} \mathrm{e}$ Nimmakayaly et al. ${ }^{22}$. Os dismorfismos faciais relatados são: braquicefalia, hipoplasia da face média, face plana, lábio fino, testa estreita e plana, região malar plana, nariz amplo e curto, pescoço curto com pele enrugada, hipertelorismo, sobrancelhas altas, dobras epicânticas do lado direto, ponte nasal e terço médio achatado, plagiocefalia, crânio em forma de caixa, fontanela anterior aberta, testa proeminente, nariz ponta nasal 
bulbosa, orelhas pequenas e orelhas protuberantes.

Em alguns casos tem sido relatada a presença de problemas esqueléticos como retrognatismo relatado por Morava et al. ${ }^{23}$ e Morava et al. $^{24}$. Micrognatia foi relatado por Morava et al. $^{23}$, Baliff et al. $^{25} \mathrm{e}$ Mickelson et al. ${ }^{16}$. Estes problemas podem levar a presença de apinhamento dentário devido à diminuição das dimensões da maxila e ao desenvolvimento de macroglossia secundária, considerando o pequeno espaço encontrado para o posicionamento da língua. Indivíduos com essa condição tendem a se sentirem mais confortáveis com a boa aberta e a língua protruída, o que faz com que a língua tenha uma aparência aumentada $^{29}$. A macroglossia provoca deslocamento dos dentes e, consequentemente, maloclusão e hábitos bucais deletérios ${ }^{30}$. Esta condição associada à hipotonicidade da língua, leva os lábios a serem frequentemente banhados por saliva, o que pode leva a queilite angular, irritação e fissuras nos cantos labiais, facilitando a instalação de processos infecciosos $^{31,32}$.

Anomalias palatais foram relatadas por Morava et al. ${ }^{24} \mathrm{e}$ Mickelson et al. ${ }^{16}$. O palato estreito e profundo, quando associado à macroglossia e protrusão da língua promove uma diminuição do volume da cavidade oral que prejudica a mastigação e a fala ${ }^{33}$. E deficiências de crescimento do terço médio da face foram relatadas por Morava et al. ${ }^{24} \mathrm{e}$ Baliff et al. ${ }^{25}$, sendo esta característica apontada por Thomas ${ }^{34}$ e Elwood et al. ${ }^{35}$ como causa para a obstrução de vias aéreas, que em muitos casos, pode requerer 0 procedimento emergencial de traqueostomia.

Deste modo, estes pacientes são considerados de alto risco para o desenvolvimento de doenças bucais, tendo uma necessidade aumentada para 0 cuidado preventivo odontológico, onde é fundamental a participação dos familiares e/ou responsáveis para 0 sucesso do tratamento e promoção da saúde bucal do paciente.

\section{Conclusão}

Os pacientes acometidos de microcefalia apresentam alterações craniofaciais típicas, que podem levar a problemas sérios, como maloclusão, problemas periodontais, obstrução das vias aéreas, problemas de fonação e processos inflamatórios.

fundamental saber reconhecer essas alterações e seus fatores limitantes no atendimento, a fim de proceder adequadamente quanto ao tratamento e reabilitação do paciente microcéfalo.

Não há protocolos de atenção odontológica e estudos avaliando as características dentárias dos pacientes acometidos com microcefalia. Com isso, fazem-se necessários estudos longitudinais para avaliação das características cranianas, faciais e dentárias em indivíduos microcéfalos, bem como um maior número de profissionais especialistas no atendimento a pacientes especiais. 


\section{Referências}

1. Cugola FR, Fernandes IR, Russo FB, et al. The Brazilian Zika virus strain causes birth defects in experimental models. Nature. Jun 9 2016;534(7606):267-271.

2. Petersen E, Wilson ME, Touch S, et al. Rapid Spread of Zika Virus in The Americas--Implications for Public Health Preparedness for Mass Gatherings at the 2016 Brazil Olympic Games. International journal of infectious diseases : IJID : official publication of the International Society for Infectious Diseases. Mar 2016;44:11-15.

3. Musso D, Nhan T, Robin E, et al. Potential for Zika virus transmission through blood transfusion demonstrated during an outbreak in French Polynesia, November 2013 to February 2014. Euro Surveill. 2014;19(14).

4. Musso D, Roche C, Robin E, Nhan T, Teissier A, Cao-Lormeau VM. Potential sexual transmission of Zika virus. Emerging infectious diseases. Feb 2015;21(2):359-361.

5. Gourinat AC, O'Connor O, Calvez E, Goarant C, Dupont-Rouzeyrol M. Detection of Zika virus in urine. Emerging infectious diseases. Jan 2015;21(1):84-86.

6. Musso D, Roche C, Nhan TX, Robin E, Teissier A, Cao-Lormeau VM. Detection of Zika virus in saliva. J Clin Virol. Jul 2015;68:53-55.

7. Dick GW, Kitchen SF, Haddow AJ. Zika virus. I. Isolations and serological specificity. Transactions of the Royal Society of Tropical Medicine and Hygiene. Sep 1952;46(5):509-520.

8. Macnamara FN. Zika virus: a report on three cases of human infection during an epidemic of jaundice in Nigeria. Transactions of the Royal
Society of Tropical Medicine and Hygiene. Mar 1954;48(2):139-145.

9. Paixao ES, Barreto F, Teixeira Mda G, Costa Mda C, Rodrigues LC. History, Epidemiology, and Clinical Manifestations of Zika: A Systematic Review. American journal of public health. Apr 2016;106(4):606-612.

10. Musso D, Nilles EJ, Cao-Lormeau VM. Rapid spread of emerging Zika virus in the Pacific area. Clin Microbiol Infect. Oct 2014;20(10):0595-596.

11. Duffy MR, Chen TH, Hancock WT, et al. Zika virus outbreak on Yap Island, Federated States of Micronesia. The New England journal of medicine. Jun 11 2009;360(24):2536-2543.

12. Zanluca C, Melo VC, Mosimann AL, Santos GI, Santos CN, Luz K. First report of autochthonous transmission of Zika virus in Brazil. Memorias do Instituto Oswaldo Cruz. Jun 2015;110(4):569-572.

13. Epidemiological Bulletin 34 Secretariat of Health Surveillance. 2015.

http://portalsaude.saude.gov.br/image s/pdf/2015/novembro/19/Microcefaliabol-final.pdf

14. Noronha L, Zanluca C, Azevedo ML, Luz KG, Santos CN. Zika virus damages the human placental barrier and presents marked fetal neurotropism. Memorias do Instituto Oswaldo Cruz. May 2016;111(5):287293.

15. Birth defects surveillance: a manual for programme managers. 2014.

http://www.who.int/iris/handle/10665/1102 $\underline{23 .}$

16. Mickelson EC, Robinson WP, Hrynchak MA, Lewis ME. Novel case of $\quad \operatorname{del}(17)(q 23.1 q 23.3) \quad$ further highlights a recognizable phenotype involving deletions of chromosome (17)(q21q24). American journal of 
medical genetics. Aug 22 1997;71(3):275-279.

17. Donna M. McDonald-McGinn KES. Chromosome 22q11.2 Deletion Syndrome (DiGeorge Syndrome/Velocardiofacial Syndrome). Medicine. 2011;90(1):118.

18. Marco PT IG, Romero RF, Cuchud AP, Vivas RF, Aytés AP. Cuarto caso de síndrome de Langer-Giedion y TRPS-1 no delecionado. Variabilidad genotipo-fenotipo. Rev Esp Endocrinol Pediatr. 2015;6(1):61-65.

19. Romina Romeo G MCP. Síndrome de Miller Dieker. Revista Anacem. $2007 ; 1$.

20. Brasil Ministério da Saúde. Diretrizes de estimulação precocezero a 3 anos com Atraso no Desenvolvimento Neuropsicomotor Decorrente de Microcefalia. 2016:123p.

21. Brasil Ministério da Saúde. Departamento de Vigilância das Doenças Transmissíveis. Protocolo de vigilância e resposta à ocorrência de microcefalia e/ou alterações do sistema nervoso central (SNC) / Ministério da Saúde, Secretaria de Vigilância em Saúde, Departamento de Vigilância das Doenças Transmissíveis. Brasília, Ministério da Saúde. 2016.

22. Nimmakayalu M, Major $H$, Sheffield V, et al. Microdeletion of 17q22q23.2 encompassing TBX2 and TBX4 in a patient with congenital microcephaly, thyroid duct cyst, sensorineural hearing loss, and pulmonary hypertension. American journal of medical genetics. Part $A$. Feb 2011;155A(2):418-423.

23. Morava E, Zeevaert R, Korsch E, et al. A common mutation in the COG7 gene with a consistent phenotype including microcephaly, adducted thumbs, growth retardation, VSD and episodes of hyperthermia. European journal of human genetics : EJHG. Jun 2007;15(6):638-645.

24. Morava E, Lefeber DJ, Urban Z, et al. Defining the phenotype in an autosomal recessive cutis laxa syndrome with a combined congenital defect of glycosylation. European journal of human genetics : EJHG. Jan 2008;16(1):28-35.

25. Ballif BC, Theisen A, Rosenfeld JA, et al. Identification of a recurrent microdeletion at 17q23.1q23.2 flanked by segmental duplications associated with heart defects and limb abnormalities. American journal of human genetics. Mar 12 2010;86(3):454-461.

26. Haddad A. Odontologia para
pacientes com necessidades especiais. 2007.

27. Siqueira WL, Moffa EB, Mussi MC, Machado MA. Zika virus infection spread through saliva--a truth or myth? Brazilian oral research. 2016;30.

28. Informe Epidemiológico № 40 Semana Epidemiológica (SE) 33/2016 (14/08/2016 A 20/08/2016) Monitoramento dos casos de microcefalia no Brasil. 2016. http://www.combateaedes.saude.gov. br/images/sala-desituacao/informe microcefalia epidem iologico40.pdf.

29. Vera Lucia Gil-Da-Silva-Lopes ELM, Fabíola Paoli Monteiro. Guia de manejo clínico para pacientes com síndrome de deleção 22q11.2. Projeto Crânio-face Brasil. 2014.

30. Cohen MM, Winer RA. Dental and Facial Characteristics in Down's Syndrome (Mongolism). Journal of dental research. Jan-Feb 1965;44:SUPPL:197-208.

31. Guedes-Pinto. Odontopediatria. 2003. 
32. Mugayar. Pacientes portadores de necessidades especiais: manual de odontologia e saúde oral.

33. Oliveira A ACB. Aspectos relacionados à saúde bucal de crianças e adolescentes com Síndrome de Down: um estudo qualiquantitativo. Rio de Janeiro: Doutorado, Escola Nacional de Saúde Pública; 2007.

34. Thomas JN. Partial upper airway obstruction and sleep apnoea. $J$ Laryngol Oto. 1978;92(1):41-46.]

35. Elwood ET, Burstein FD, Graham L, Williams JK, Paschal M. Midface distraction to alleviate upper airway obstruction in achondroplastic dwarfs. The Cleft palate-craniofacial journal: official publication of the American Cleft Palate-Craniofacial Association. Jan 2003;40(1):100-103. 